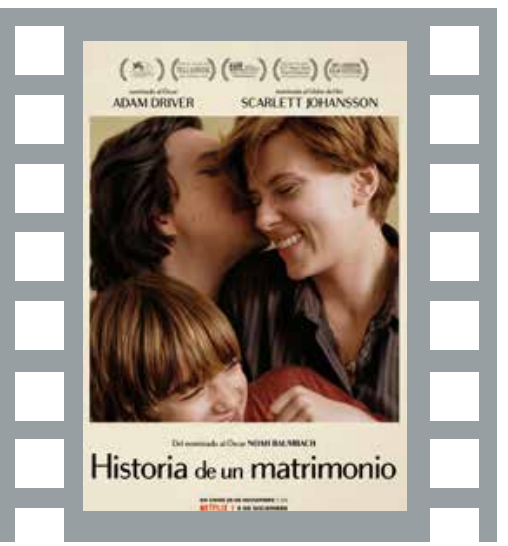

\section{Ficha têcnica}

Título original: Marriage Story

Nacionalidad: Estados Unidos

Dirección: Noah Baumbach

Guion: Noah Baumbach

Productora: Heyday Films, Netflix

Año: 2019

Interpretación: Adam Driver (Charlie Barber); Scarlett Johansson (Nicole Barber); Laura Dern (Nora Fansahw); Ray Liotta (Jay Marotta); Alan Alda (Bert Spitz); Julie Hagerty (Sandra): Merrit Wever (Cassie); Azhy Robertson (Henry Barber); Wallace Shawn (Frank); Mark O’Brien; Mickey Sumner (Beth); Marta Kelly (Nancy Katz); Gideon Glick (actor de teatro) Mattew Maher (actor de teatro): Jasmine Cephas (actriz de teatro) Brooke Bloom (Mary Ann); Mary Wiseman (actriz de teatro)

Música: Randy Newman

Fotografía: Robbie Ryan

Género: Drama, familia, divorcio

Duración: 136 minutos

Premios: 2020 | Premios Oscar: 6 nominaciones, entre ellas mejor actriz secundaria (Laura Dern); Globos de Oro: 6 nominaciones, entre ellas mejor actriz secundaria (Laura Dern): Premios BAFTA: 5 nominaciones, entre ellas mejor actriz secundaria (Laura Dern); Círculo de críticos de Nueva York: mejor actriz secundaria (Laura Dern); Premios Guldbagge (Suecia): nominada a mejor película extranjera; British Independent Film Awards (BIFA): nominada a mejor película internacional.

Trailer: https://www.youtube.com/watch?v=hFqHmqB5LIk

\title{
Historia de un matrimonio
}

Si lloras por haber perdido el sol, las lágrimas no te dejarán ver las estrellas. Rabindranath Tagore

\section{Carmen Pereira Domínguez y Juan Antonio Rodríguez} Hernández

\author{
mcdguez@uvigo.es y jrodriz@ull.edu.es
}

\section{La historia}

Se aborda el proceso de divorcio de una pareja con un hijo que ejerce su carrera profesional en ciudades distantes entre sí (Los Ángeles y New York). La peculiaridad de esta familia es que pertenece al mundo escénico: Charlie, el padre, es director de teatro y Nicole, la madre, es actriz. Por lo demás, se evidencia un modelo de familia nuclear con un padre, una madre y un hijo; un contexto que sin duda ayudará a los espectadores a conectar con el argumento.

Se trata de la historia de un profundo desencuentro entre la pareja que termina en divorcio, a pesar de las variadas señales de cariño que apreciamos a lo largo de todo el metraje. Asimismo, se observan pequeños roces y acaloradas discusiones fuera de tono. No obstante, esta vivencia se aleja de cualquier acto violento y busca el equilibrio entre las voces de los personajes y la crudeza de la misma separación. Henry es el hijo de ocho años del matrimonio que vivirá de cerca el proceso de divorcio de sus padres; poco a poco comprenderá que su relación con ellos cambiará para siempre y el amor que le profesan consolidará el respeto y la afectividad entre ambos.

\section{Temas}

Comunicación

Conciliación familiar

Conflictos familiares

Crecimiento personal

Divorcio

Educación emocional

Educación familiar

Identidad personal

Mediación

Relaciones familiares

\section{Valores}

Amor
Autoestima
Compromiso
Convivencia
Diálogo
Fidelidad
Perdón
Respeto
Sensibilidad
Tolerancia

\section{(r.) Antes de ver la película}

1. Indagamos sobre las cifras de divorcio en España https://www.ine. es/dyngs/INEbase/es/operacion.htm?c=estadistica_C\&cid=12547 $36176798 \&$ menu=ultiDatos\&idp=1254735573206. Y sobre las críticas de los resultados de los datos del uso de la mediación, https:// www.poderjudicial.es/cgpj/es/Temas/Mediacion/Datos-mediacionintrajudicial/Mediacion-intrajudicial-en-Espana--datos-2015

2. Aunque el divorcio no es tal hasta que legalmente se lleva a cabo, hay diferentes formas de afrontar el proceso. Construye un esquema de las formas de hacer frente al desarrollo de divorcio https:// www.divorcios.me/consejos-basicos-afrontar-divorcio-hijos/

3. La mediación, como una forma de encarar el divorcio, está reconocida en España a través de la Ley 3/2007, de 23 de marzo, de Mediación Familiar, pero iconocéis a parejas que la hayan utilizado?, ¿cuál es su valoración?, ¿y la vuestra? https://www.boe.es/ buscar/pdf/2007/BOE-A-2007-13751-consolidado.pdf

Parkinson, L. (2005). Mediación familiar. Teoría y práctica: principios y estrategias operativa. Barcelona: Gedisa.

4. El divorcio es una situación de conflicto donde las emociones juegan un papel esencial. ¿Qué emociones consideráis que se activan en los procesos de divorcio? Bisquerra, R. (2011). Educación emocional. Padres y Maestros, (337), 5-8. https://revistas.comillas. edu/index.php/padresymaestros/article/view/272/207

5. El divorcio afecta a toda la familia, no solo a los cónyuges. Golombok, S. (2016). Familias modernas. Padres e hijos en las nuevas formas de familia. Madrid: Siglo XXI.

6. Nos informamos y definimos la conciliación familiar. ¿Creéis que en vuestra familia existe conciliación familiar? Barraca, J. (2010). Conflictos familiares entre padres e hijos jóvenes, (355), 10-15. https://revistas.comillas.edu/index.php/padresymaestros/article/view/1183/1004. Maganto, J. M. (2012). Concilia en tu vida. Conciliación de la vida personal, familiar y académico-laboral en adolescentes, jóvenes y adultos. Madrid: Pirámide.

7. Historia de un matrimonio es un filme que recomendamos para familias, jóvenes y educadores. Analizamos su carátula: imágenes y título. ¿Cuál será el argumento de esta película? Elaboramos una breve reflexión sobre ello y la contrastaremos una vez visto el filme. 


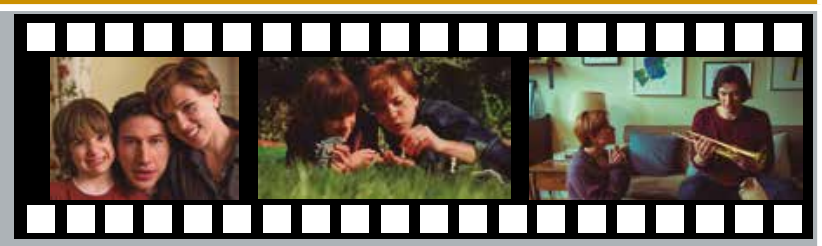

1.1. La película comienza con un primer plano de Nicole actuando, le sigue una variedad de situaciones de la vida diaria donde Charlie cuenta todo lo que le agrada de Nicole: "cuando va por la calle y escucha a las personas; es buena ciudadana. Sabe salvar los malos rollos familiares. Corta el pelo a la familia. Siempre tiene un té preparado que nunca se toma. No es ordenada, pero lo intenta por agradar. Creció en Los Ángeles entre actores; se lleva bien con su madre y hermana. Es una buena madre; juega a conciencia; es competitiva. Tiene fuerza en los brazos y me parece sensual; la nevera siempre está llena y nadie pasa hambre. Lo dejó todo por venirse conmigo a Nueva York. Baila genial y anima a acompañarla. No disimula, dice las cosas claras. Pone en práctica las ideas más estrambóticas. Es mi actriz favorita". (00:00:15 - 00:03:44).

1.2. Asimismo, Nicole también describe lo que más le agrada de Charlie: "es imperturbable; siempre realiza lo que piensa. Cuando come devora sin parar. Es muy ordenado. Cuida el ahorro energético. Cocina, cose y plancha. Viste muy bien. Nunca se siente derrotado; es muy competitivo. Aguanta las rabietas y adora ser padre. Se pierde en su propio mundo. Dice cosas sin que te avergüences. Charlie se ha hecho a sí mismo. A sus padres solo los he visto una vez, pero pasó una infancia entre alcohol y episodios violentos. Se fue a vivir a Nueva York desde Indiana, sin apoyo. Es conciliador y crea buen ambiente en el trabajo. Sabe lo que quiere, no como yo que nunca lo tengo claro" (00:03:45 - 00:07:40).

1.3. Charlie es un notorio director de teatro en la ciudad de Nueva York Su compañía de teatro estrena una obra protagonizada por su esposa, Nicole, una conocida exactriz de cine. Ante el momento de crisis matrimonial por el que pasan acuden a un mediador quien les sugiere que cada uno escriba lo que le agrada del otro, pero Nicole descarta leerlo en alto y deciden renunciar a esta opción mediadora (00:07:51 - 00:09:22).

La noche antes de su viaje a Los Ángeles, la compañía despide a Nicole en su última actuación. Luego la pareja regresa tensa a casa (00:09:23 - 00:15:15).

1.1. ¿Qué os sugiere la descripción del marido? ¿Qué más situaciones valora Charlie de Nicole? ¿Qué ámbitos aborda el relato? ¿Cómo nos sentimos viendo las imágenes? ¿En qué tono se exponen esas vivencias? ¿Refleja la vida de esta familia? ¿Qué costumbres, normas y gustos tienen? ¿Cómo educa a su hijo? Analizamos el lenguaje coloquial que utilizan. ¿Qué valores sobresalen? ¿Se muestran las debilidades de Nicole? ¿Se aprecian problemas latentes en esta relación? ¿Os parece que sea una pareja en proceso de divorcio? ¿Cómo termina esta escena? Evaluamos esta descripción. ¿Qué tipo de música escuchamos?

1.2. ¿Qué os sugiere la descripción de Nicole sobre su marido? ¿Cuá es el tono utilizado? ¿Qué ámbitos aborda el relato? ¿Qué más situaciones comenta? ¿Qué valores se reflejan? ¿Hay diferencias con respecto a la descripción de Charlie sobre ella? ¿Presenta las debilidades de Charlie? ¿Se compara con él? ¿Cómo se siente a su lado? ¿Es apreciado en su trabajo? ¿Os parece que sea una pareja en proceso de divorcio? ¿Se preocupa de la educación de su hijo? ¿Se detectan problemas en la relación? ¿Qué diferencias familiares tienen? ¿Cómo nos sentimos viendo estas escenas? ¿Cómo es la música de fondo?

1.3. ¿Por qué Nicole se niega a leer su reflexión? ¿Qué les comenta el mediador? ¿Qué ventajas tiene elaborar un escrito así? ¿Creéis adecuada la actuación del mediador? ¿Cómo podría haber reconducido la situación?

¿Cómo se muestran Nicole y Charlie ante el grupo de trabajo que despide a Nicole? Una vez en casa, ¿sobre qué conversan?, y ¿cómo se sienten? ¿Han tratado con el hijo su situación?

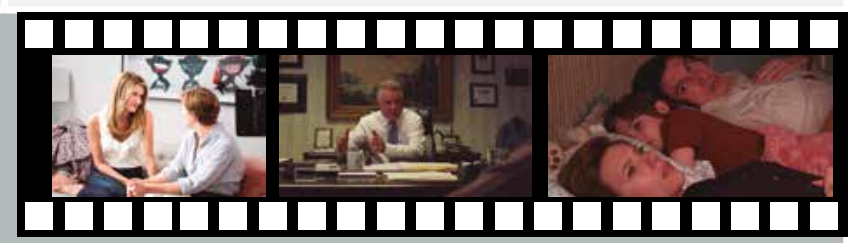

2.1. Nicole vivirá con Henry temporalmente junto a su madre en Los Ángeles ya que le ofrecen ser protagonista en un piloto de televisión. Mientras, Charlie permanecerá en Nueva York ya que pronto la compañía de teatro se trasladará a Broadway (00:15:15 - 00:17:27).

2.2. Aunque la pareja acordó separarse amistosamente, Nicole contacta con la abogada de familia Nora Fanshaw. En un ambiente próximo e íntimo le anima a que Nicole cuente su historia y ella le habla de su relación con Charlie, de cómo se fueron distanciando, sobre sus ideas y deseos incumplidos y de una posible infidelidad (00:21:28 - 00:22:39 y 00:22:27 - 00:25:11). Nora le expone lo que va a hacer por ella y realiza valoraciones de la situación y de Charlie. En ocasiones, Nicole muestra afecto y le desea lo mejor a Charlie (00:25:22 - 00:32:04)

2.1. Detallamos la vida de Nicole y Henry en casa de su madre. ¿Qué normas de convivencia les recuerda ella? ¿Qué relación mantiene con su hermana y su familia? ¿Cómo vive Henry este cambio? ¿Se flexibilizan las normas? ¿Cómo se comunica con su padre?

2.2. ¿Qué opináis del ambiente y la forma en que recibe Nora a Nicole? ¿Sabe la abogada algo de Nicole? ¿Qué aspectos comparte con ella? ¿Cómo veis el abrazo de Nora a Nicole? ¿Qué os parece el compromiso establecido entre ambas? ¿Cuál es el acto de esperanza? ¿Qué piensa la abogada de Charlie? ¿Hay insultos hacia él? ¿Empatiza con Nicole? ¿Cómo cuenta Nora su propio divorcio? ¿Qué comenta de los maridos? ¿Está situada en una estrategia de ganar/perder o de ganar/ganar? ¿Habla de dinero? 


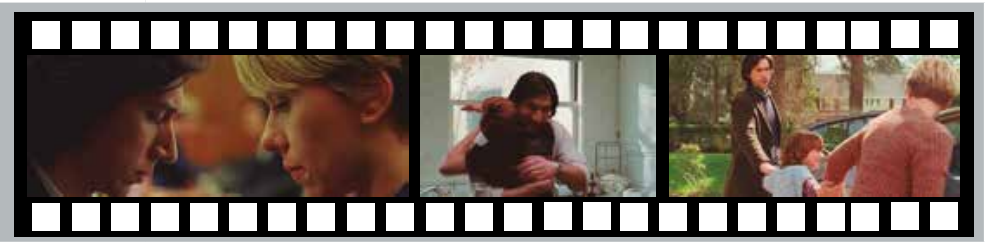

3.1. Quince días después, Charlie visita a Nicole e hijo y esta le entrega los papeles de divorcio. Charlie contacta con Jay Marotta, un costoso y atrevido abogado que lo incita a luchar y a jugar sucio, pero renuncia y regresa a Nueva York (00:44:10 - 00:44:39). Vuelve a Los Ángeles y contrata a Bert Spitz, un abogado familiar más conciliador. Charlie evita ir al juzgado, por lo que Bert organiza una reunión junto a Nora y Nicole. La abogada alega que Charlie se negó a respetar los deseos de Nicole de retornar a Los Ángeles y que Henry preferiría estar con su madre.

3.2. El abogado describe la situación y los errores cometidos por Charlie (00:44:40 - 00:46:00).

Bert recomienda en privado a Charlie que abandone su residencia en Nueva York por completo, pero un frustrado Charlie se niega y decide despedirlo.

3.3. Cambiando el relato. Los abogados hablan de Nicole, Charlie cree en su esposa y no entiende la estrategia planteada por los juristas. Charlie está desconcertado y les comenta que Nicole y él no van con esa intención que le plantean estos expertos y Charlie se marcha (00:46:46 - 00:48:44).
3.1. ¿Qué pensaba Charlie sobre el trabajo de Nicole en Los Ángeles? ¿Qué se imagina cuando Nicole le entrega los papeles sobre el divorcio? ¿Cómo se queda ante la actitud tajante de Nicole? ¿Qué era lo que quería Charlie? Y, ¿qué os sugiere este ambiente y la forma en que reciben los abogados a Charlie? ¿Empatizan con Charlie? ¿Establecen una relación cordial, de seguridad? ¿Hablan de dinero? ¿Por qué el abogado Bert le aconseja que alquile un apartamento en Los Ángeles para estar más cerca de su familia y fortalecer su caso de custodia?

3.2. ¿Qué opinión os merece la descripción de la situación de Charlie? ¿Creéis que Charlie es consciente de las implicaciones de su divorcio? ¿Qué sabe el abogado de la vida de Charlie?

3.3. ¿En qué consiste el cambio de relato que proponen los abogados? Respecto a Nicole, ¿es diferente el planeamiento de los letrados y el de Charlie? ¿Cómo valoráis la explicación que hace el abogado de los acuerdos? ¿Están situados en una estrategia de ganar/perder o de ganar/ganar? ¿Hay insultos hacia Nicole?

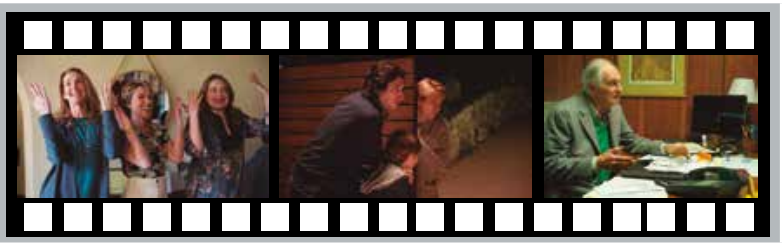

4.1. Charlie y Henry visitan un nuevo abogado. Este le cuenta su verdad y su trato con sus clientes, es decir, ante todo son personas. Le plantea los gastos que supone llevar a cabo el proceso de divorcio. Le pregunta si quiere ser mejor marido en el divorcio. Mientras, Henry se aburre de tantas visitas a oficinas y añora no poder jugar con su padre (01:01:37 - 01:02:17).

4.2. El abogado le recuerda que el problema es de Nicole y él y que deberían solucionarlo mejor ellos dos solos. Le recuerda, "tanto si ganamos como si no, serán ustedes dos quienes tengan que resolverlo juntos". El abogado abraza a Charlie (01:02:18 - 01:03:31).

4.3. Esta secuencia está más alejada de la anterior, pero es esencial para entender otra forma de abordar el divorcio por el letrado. Reunidos en una pequeña sala el abogado aborda la situación y la necesidad de llegar a un acuerdo amistoso con Charlie 101:17:57 $-01: 22: 04)$.

Después de la frustrante primera vista ante el juez. Charlie y Nicole intentan dialogar en privado

5.1. Ante el decepcionante proceso legal por el que pasan Charlie y Nicole deciden verse a solas sin presencia de abogados. Lo que parecía un encuentro amistoso se convierte en una penosa discusión. Nicole le dice a Charlie que su egoísmo se ha convertido en el foco de atención. La discusión va cobrando tal tensión que Charlie golpea la pared y hace un orificio. Desesperado, grita y desea la muerte de Nicole, se derrumba y le pide disculpas. Nicole lo conforta y también se excusa. Se evidencia un diálogo donde ninguno entiende lo que dice el otro (01:30:45 - 01:40:54).
4.1. ¿Qué os trasmite el ambiente y la forma en la que recibe e abogado a Charlie? ¿Qué opináis de las valoraciones que hace el abogado sobre el divorcio? ¿Veis diferencias con los otros colegas? ¿Y con Nora? ¿Habla de dinero? Describid el comportamiento del hijo ante los diversos contactos que realizan. ¿Qué dudas le surgen y cuáles son las respuestas de su padre?

4.2. Valorad la actuación del abogado. ¿Cómo os sentís al ver esa imagen? ¿Creéis que es un abrazo sincero? ¿Qué os parecen las palabras que dice Charlie, emocionado, al abogado?

4.3. ¿Qué valoraciones hacéis sobre la explicación que hace el abogado de la situación? ¿Cómo se siente Charlie y cuál es su deseo? ¿Quién debe ganar según el abogado? ¿Se sitúa en una estrategia de ganar/perder, de ganar/ganar o bien de no perder?

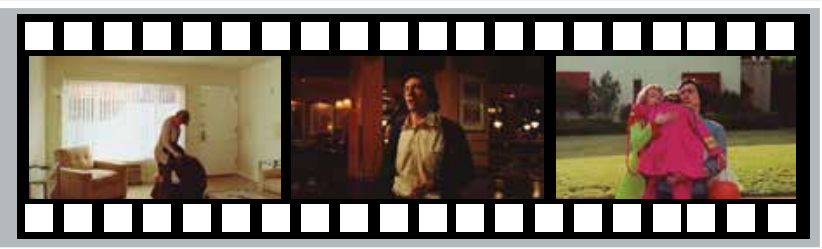

5.1. ¿Qué os parece que la pareja dialogue sola? ¿Es posible mantener a Henry al margen? ¿Hablan de dinero? ¿Qué sensación produce ver a la pareja sentada y distanciada? Analizad su reacción, la de ella, al percatarse de sus palabras y la de él, ¿qué ha cambiado entre ellos? ¿Se están escuchando? Más allá de los reproches, ¿podéis identificar el problema de fondo de su relación?, ¿creéis que lo han abordado? pe/cine/historia-matrimonio-noah-baumbach-habla-fuerte-peleaentre-charlie-y-nicole-noticia-113160/
El Director nos comenta: https://www.americatv.com.pe/cinesca- 
5.2. Unos días después una persona experta, Nancy, evaluará cómo se comportan Nicole y Charlie con su hijo. Además, la pareja pacta reducir sus demandas y equilibrar el acuerdo para finalizar el divorcio, aunque Nora conseguirá mejores condiciones para Nicole (01:42:21 - 01:45:15 y 01:46.44 - 01:55:15).

5.3. Pasa un año y la obra de teatro de Charlie es un éxito en Broadway. Además, gracias a que consigue la Beca MacArthur, permanecerá un año en la Universidad de California y vivirá en Los Ángeles, así, disfrutará más de Henry. Mientras, Nicole rehace su vida y está nominada a un Premio Emmy por la dirección del capítulo de la serie (02:04:06 - 02:11:42)
5.2. ¿Qué le comenta sobre esta evaluación Nicole a Charlie? Relatamos y valoramos la visita de Nancy al apartamento que habitan Charlie y Henry. ¿En qué se fija y qué comentarios hace? ¿Cómo actúa Charlie con su hijo? Y, ¿qué pensáis sobre los consejos de Nora a Nicole sobre la perfección de la mujer y su relación con esta supervisión?

5.3. Pensamos en los cambios ocurridos en estas tres personas durante este año de separación. En la emoción que siente Charlie al leer lo escrito por Nicole sobre lo que le agradaba de él. ¿Cómo es ahora la relación entre ellos? Con respecto a Henry, ¿qué priorizan ahora $\mathrm{Ni}$ cole y Charlie? ¿Mejoran las normas establecidas con Henry? ¿Con qué escena termina la película? ¿Qué mensaje nos transmite?

\section{Aleunas curiosidades de interés}

1. El director, Noah Baumbach, nació en Brooklyn, en Nueva York. Su padre fue docente en la Universidad de Stanford y crítico de cine. Su madre escribió sobre ficción y fue crítica de cine. Desde muy joven Noah quiso ser cineasta.

2. En 1987 se graduó en la escuela secundaria Midwood de Brooklyn y en 1991 se licenció en inglés en la Universidad de Vassar College.

3. Baumbach se casó en el año 2005 con la actriz Jennifer Jason Leigh y tuvieron un hijo. El matrimonio duró cinco años y en 2013 se divorciaron. Desde el año 2011 mantiene una relación con la estadounidense Greta Gerwing, es actriz, directora y guionista.

4. El cine de Baumbach combina humanismo con sensibilidad y cierto sentido del humor. Se inspira en Ingmar Bergman (Secretos de un matrimonio. Suecia, 1974) y en Woody Allen (Manhattan. Estados Unidos, 1979).

5. También refleja su experiencia como hijo adolescente con padres separados en su película Una historia de Brooklyn (2005). En el año 2010 vivió un duro proceso de separación de su mujer que plasma en el guion de Historia de un matrimonio.
6. Esta película, rodada en Los Ángeles y Nueva York se estrenó con éxito en el Festival de Cine de Venecia y se lanzó en Netflix en el 2019. Está considerada como uno de los mejores trabajos de su director.

7. Randy Newman, se ha encargado de la música del filme, es un reconocido compositor estadounidense de bandas sonoras de cine https://es.wikipedia.org/wiki/Randy_Newman

8. La crítica ha recibido con elogios el guion y la dirección de Baumbach. Igualmente, las interpretaciones de Scarlett Johansson (que vivía un proceso de divorcio), Adam Driver y Laura Dern son magistrales. Por todo ello, la película está valorada entre las diez mejores del año 2019

https://es.wikipedia.org/wiki/Noah_Baumbach

https://es.wikipedia.org/wiki/Scarlett_Johansson

https://es.wikipedia.org/wiki/Adam_Driver

https://es.wikipedia.org/wiki/Laura_Dern

\section{Actividades de experiencia, referiôn y acciôn en común}

1. Nos informamos sobre la trayectoria profesional del fotógrafo Robbie Ryan. https://en.wikipedia.org/wiki/Robbie_Ryan_(cinematographer)

Este experto irlandés en cinematografía ha colaborado con directores de películas muy conocidas, El estilo visual del cinefotógrafo de Robbie Ryan https://enfilme.com/notas-del-dia/video-el-estilovisual-del-cinefotografo-robbie-ryan

Analizamos su trabajo en esta película y destacamos su forma de mostrar situaciones de la vida de los diversos personajes.

2. Mientras Nicole habla con Norma, la abogada de familia, hace referencia al documental sobre George Harrison (M. Scorsese, Estados Unidos, 2011) https://www.filmaffinity.com/es/film962883. html concretamente, a la historia de amor entre el músico y Olivia Arias que lo salvó del mundo de las drogas y de un atentado, https://www.gq.com.mx/entretenimiento/articulo/olivia-ariasmexicana-que-enamoro-george-harrison

Indagad sobre el tema y justificad los motivos por los que Nicole cita la vida de estas dos personas. ¿Qué relación hay con su matrimonio? ¿Qué desearía Nicole? ¿Cómo se siente ante lo que está viviendo?

3. Escuchamos la canción que interpreta Charlie, Being Alive, que pertenece al musical Company, estrenado en Broadway, en 1970, obra del famoso Stephen Sonheim, https://www.letras.com/son- dheim-stephen/being-alive/traduccion.html es un reflejo de los tristes momentos por los que pasa Charlie y la esperanza, en un futuro, de lograr una nueva oportunidad de enamorarse. Comentamos los sentimientos que afloran en Charlie.

https://es.vida-estilo.yahoo.com/netflix-historia-de-un-matrimonio-adam-driver-cancion-being-alive-192301931.html

4. En varias críticas cinematográficas se compara la famosa película Kramer contra Kramer (R. Benton, Estados Unidos, 1979) https:// www.filmaffinity.com/es/film257947.html con Historia de un matrimonio. A pesar de transcurrir casi cuarenta años sería interesante comentarlas y así comprobar sus evidentes diferencias: dirección, narración, personajes, legislación, prejuicios, educación emocional...

5. ¿Qué otras películas podemos recomendar vinculadas con el proceso de divorcio?

6. Llegados a este punto, retomamos la reflexión realizada al principio sobre la carátula de Historia de un matrimonio y ahora valoramos la película ya vista, su planteamiento y desarrollo en esta guía cinematográfica. Realizamos una estimación final del guion, de la fotografía, de las fortalezas y debilidades de sus personajes, de la música, de las emociones suscitadas, de los valores expuestos, de los interrogantes surgidos... ¿Qué conocimientos nos ha aportado? 